\title{
Molecular Epidemiology of Apparent Outbreak of Invasive Aspergillosis in a Hematology Ward
}

\author{
ALEXANDER LEENDERS, ${ }^{1}$ ALEX VAN BELKUM,${ }^{1 *}$ SASKIA JANSSEN,${ }^{1}$ SIEM DE MARIE, ${ }^{1}$ \\ JAN KLUYTMANS,${ }^{1} \dagger$ JENNE WIELENGA, ${ }^{2}$ BOB LÖWENBERG ${ }^{2}$ \\ AND HENRI VERBRUGH ${ }^{1}$ \\ Department of Bacteriology ${ }^{1}$ and Department of Hematology, ${ }^{2}$ University \\ Hospital Dijkzigt, 3015 GD Rotterdam, The Netherlands
}

Received 3 July 1995/Returned for modification 25 August 1995/Accepted 8 November 1995

\begin{abstract}
During a 2-month period, five patients suffering from invasive infections caused by Aspergillus flavus or Aspergillus fumigatus were identified in the Hematology Department of the University Hospital Dijkzigt (Rotterdam, The Netherlands). To study the epidemiological aspects of invasive aspergillosis, strains from these patients and from the hospital environment, isolated during extensive microbiological screening, were subjected to genotyping. A novel DNA extraction technique, involving freezing, grinding, and direct lysis in guanidium isothiocyanate-containing buffers of mycelial material, was applied. DNA isolation was followed by typing by random amplification of polymorphic DNA (RAPD) analysis. This showed that strains isolated from all patients infected with the same fungal species were genotypically distinct, thus providing evidence against the possibility of an ongoing, single-source nosocomial outbreak. Strains could also be differentiated from strains of geographically diverse origins. However, an A. flavus strain from one of the patients was also frequently encountered in the hospital environment. As all environmental strains were collected after this patient had been diagnosed with invasive disease, the epidemiological value of this observation could not be ascertained. Intensive investigations showed no single source of $A$. flavus or other aspergilli. RAPD genotyping proved that the outbreak of invasive aspergillosis in the hematology ward consisted of a series of unrelated events and was not due to a common source within the hospital. RAPD fingerprinting of aspergilli may greatly facilitate future investigations of the epidemiology of invasive disease caused by these pathogens.
\end{abstract}

Aspergillus spp. are widely distributed fungi which, after their conidia are inhaled, can cause invasive, usually pulmonary infection in immunocompromised patients (19). In oncology patients with prolonged neutropenia, Aspergillus sp. infections represent an increasing problem (1). Aspergillus fumigatus is by far the predominant species in cases of invasive disease; $A$. flavus is isolated less frequently but more often causes extrapulmonary invasive infections $(2,13)$. As the prophylactic and therapeutic efficacies of the present antifungal agents are insufficient in many cases, it is important to protect susceptible patients from inhaling Aspergillus conidia. Adequate protective isolation by using high-efficiency particulate air (HEPA) filtration currently provides the best barrier against invasive fungal disease. Nevertheless, small outbreaks of nosocomial aspergillosis have been reported, sometimes in association with environmental sources of conidia $(23,26)$. Elucidation of the complex epidemiology in such cases requires detailed molecular typing studies. However, not all of the molecular procedures are applicable to fungal typing $(12,15,22,23)$.

During an apparent outbreak of nosocomial aspergillosis in the University Hospital Rotterdam, clinical and environmental isolates of $A$. flavus and $A$. fumigatus were collected. The possible role of Aspergillus genotyping in managing such outbreaks was investigated, and measures taken at the time of the outbreak were retrospectively reevaluated. The present report describes a novel DNA extraction method and the application of randomly amplified polymorphic DNA (RAPD) analysis as

\footnotetext{
* Corresponding author. Mailing address: Dept. of Bacteriology, University Hospital Dijkzigt, Dr. Molewaterplein 40, 3015 GD Rotterdam, The Netherlands. Phone: 31-10-4635813. Fax: 31-10-4633875.

$\dagger$ Present address: St Ignatius Hospital, Department of Medical Microbiology, 4800 RK Breda, The Netherlands.
}

a genotyping method. The value of different primers for distinguishing among strains of $A$. flavus as well as $A$. fumigatus was determined.

\section{MATERIALS AND METHODS}

The epidemiological and patient-related procedures and the laboratory techniques for typing of isolates of Aspergillus spp. are described below under two separate headings.

Patients and environmental screening. (i) Invasive aspergillosis. A patient was diagnosed to have invasive aspergillosis when Aspergillus spp. were cultured, in the absence of other pathogens which could explain clinical symptoms, from bronchoalveolar lavage (BAL) fluid or from deep tissue specimens. Invasive disease was confirmed by histopathology. X-ray analysis and drug response were also used to corroborate the diagnosis of invasive disease. Five patients within the hematology ward were diagnosed with invasive aspergillosis during the period from May to July 1994.

(ii) Prophylaxis. To prevent development of invasive aspergillosis in other patients, prophylactic measures were taken. Windows were kept closed throughout the entire hospital. Patients in the hematology ward received one of two antifungal prophylactic regimens on a daily basis: $10 \mathrm{mg}$ of aerosolized amphotericin B in combination with either itraconazole ( $200 \mathrm{mg}$ orally) or amphotericin $\mathrm{B}(0.5 \mathrm{mg} / \mathrm{kg}$ of body weight intravenously). This last regimen was given to patients who were neutropenic (neutrophilic granulocyte count of less than $0.5 \cdot 10^{9}$ ) during the outbreak period, because of potential exposure to high levels of fungal conidia.

(iii) Air sampling. To study the numbers of conidia in the hospital air, serial air samples of $1 \mathrm{~m}^{3}$ each were taken twice a week with a surface air system sampler containing Sabouraud agar plates, which were incubated at 22 and $37^{\circ} \mathrm{C}$ to examine growth of both nonpathogenic and pathogenic fungi. Similar air samples were taken just outside the hospital and at a nearby demolition site.

(iv) Air-conditioning and filtration systems. To allow investigation of the air-conditioning systems and HEPA filters, patients were temporarily moved to a new building. During the first 2 weeks of closure of the old department, severa air samples were taken. After this period, the ceilings were removed and analyzed for fungal growth. The air-conditioning and filtration systems were opened and also studied. Swabs and air samples were taken from within the systems and other suspicious sites. HEPA filters were removed and studied for fungal growth, and new filters were installed.

Fungal strains and DNA typing. (i) Fungal isolates. Isolates of A. flavus and 
TABLE 1. DNA sequences of primers used

\begin{tabular}{lllc}
\hline Primer $^{a}$ & \multicolumn{1}{c}{ Code } & \multicolumn{1}{c}{ Sequence $\left(5^{\prime}-3^{\prime}\right)$} & Source or reference \\
\hline E1 & ERIC-1 & CAC TTA GGG GTC CTC GAA TGT A & 26 \\
E2 & ERIC-2 & AAG TAA GTG ACT GGG GTG AGC G & 26 \\
3 & RAPD-1247 & AAG AGC CCG T & This study \\
4 & RAPD-1254 & CCG CAG CCA A & This study \\
5 & RAPD-1281 & AAC GCG CAA C & This study \\
6 & RAPD-1283 & GCG ATC CCC A & This study \\
26 & BG-2 & TAC ATT CGA GGA CCC CTA AGT G & This study \\
28 & REP 2-I & ICG ICT TAT CIG GCC TAC & 26 \\
sp1 & Spacer-1 & TTG TAC ACA CCG CCC GTC A & 10 \\
sp2 & Spacer-2 & GGT ACC TTA GAT GTT TCA GTT C & 10 \\
\hline
\end{tabular}

${ }^{a}$ Primers 3 and 4 and primers 5 and 6 were used in combination in one assay.

A. fumigatus were collected from patients with invasive aspergillosis nursed in the hematology ward of the University Hospital Dijkzigt (Rotterdam, The Netherlands). Additional isolates were collected from patients treated on other wards and from various environmental sources (within and outside the hospital). Additional clinical isolates of A. flavus were obtained from the Department of Medical Microbiology, University Hospital Nijmegen (Nijmegen, The Netherlands), the Regional Laboratory for Public Health Haarlem (Haarlem, The Netherlands), and the Diagnostic Microbiology Laboratory of the University of Minnesota (Minneapolis). Species were identified on the basis of culture characteristics and morphology of conidiophores and conidia. Strains were propagated on Sabouraud media and stored at $-70^{\circ} \mathrm{C}$ in brain heart infusion (BHI) broth containing $10 \%$ glycerol.

(ii) Fungal DNA isolation. Strains were inoculated in $25 \mathrm{ml}$ of Sabouraud maltose medium containing $4 \mathrm{mg}$ of gentamicin per $\mathrm{ml}$, and the culture was incubated at $37^{\circ} \mathrm{C}$ for $72 \mathrm{~h}$ until abundant mycelial growth was observed. The entire thallus was collected in a porcelain bowl. Liquid nitrogen was added, after which grinding of the frozen material took place. Between 10 and $25 \mathrm{ml}$ of lysis buffer (0.1 M Tris-HCl [pH 6.4], 40 mM EDTA [pH 8.0], 1\% Triton X-100, 4 M guanidium isothiocyanate) was added, work being carried out in a safety cabinet. This suspension could be stored for various periods at $-20^{\circ} \mathrm{C}$. DNA degradation was prohibited by the immediate lysis of destroyed cells and guanidium isothiocyanate-induced protein denaturation. One milliliter of the extract was centrifuged for $5 \mathrm{~min}$ (15,000 rpm) (Eppendorf centrifuge; Merck). To the supernatant, $100 \mu \mathrm{l}$ of a Celite suspension $(200 \mathrm{mg} / \mathrm{ml}$ ) (Aoroa organics, Grel, Belgium) was added, and this suspension was shaken vigorously by hand. The pellet was washed three times in a second lysis buffer (0.1 M Tris- $\mathrm{HCl}$ [pH 6.4], $4 \mathrm{M}$ guanidium isothiocyanate), $70 \%$ ethanol, and acetone, respectively (4). After being dried, the pellet was resuspended in $150 \mu \mathrm{l}$ of $10 \mathrm{mM}$ Tris- $\mathrm{HCl}(\mathrm{pH} 8.0)$ and incubated at $56^{\circ} \mathrm{C}$ for $10 \mathrm{~min}$. Approximately $125 \mu \mathrm{l}$ of the supernatant was collected. The DNA concentration was estimated by electrophoresis of DNAcontaining aliquots through $1 \%$ agarose gels, run in $0.5 \times$ Tris-borate-EDTA in the presence of ethidium bromide, and comparison with the staining intensities of known amounts of bacteriophage lambda DNA.

(iii) PCR-mediated DNA fingerprinting. DNA typing by RAPD was performed as described previously $(14,24,25)$. Approximately $50 \mathrm{ng}$ of fungal DNA was subjected to 40 cycles of repeated denaturation $\left(1 \mathrm{~min}, 94^{\circ} \mathrm{C}\right)$, primer annealing $\left(1 \mathrm{~min}, 25^{\circ} \mathrm{C}\right)$, and enzymatic chain extension $\left(2 \mathrm{~min}, 74^{\circ} \mathrm{C}\right)$ in $100 \mu \mathrm{l}$ of a buffer system consisting of $10 \mathrm{mM}$ Tris- $\mathrm{HCl}$ (pH 9.0), $50 \mathrm{mM} \mathrm{KCl}, 2.5 \mathrm{mM}$ $\mathrm{MgCl}_{2}, 0.01 \%$ gelatin, $0.1 \%$ Triton $\mathrm{X}-100,0.2 \mathrm{mM}$ deoxynucleoside triphosphates, 50 pmol of primer, and $0.5 \mathrm{U}$ of Thermus thermophilus DNA polymerase (Sphaero Q, Leiden, The Netherlands). Initially, the enterobacterial repetitive intergenic consensus primers ERIC-1 and ERIC-2 were employed in separate assays (see Table 1 and reference 26). Sixteen additional primers were evaluated with respect to their resolving power towards Aspergillus sp. DNA. The additional primers selected on the basis of these experiments are listed in Table 1 . The resulting banding patterns were indexed by capital lettering, and even a single band difference led to a different letter code. Differences in ethidium bromide staining intensities were ignored. Upon combination of the results of multiple assays, a single, 7-letter genocode was deduced. Banding patterns were interpreted visually by three independent persons. Reproducibility and reliability were assessed as suggested previously (23).

(iv) PCR ribotyping. PCR ribotyping was performed as described for a number of bacterial pathogens $(5,9)$. With primers $\mathrm{sp} 1$ and $\mathrm{sp} 2$ (see Table 5), the $16 \mathrm{~S}$-23S intergenic spacer region was amplified by using a PCR program consisting of 40 cycles of alternating denaturation $\left(1 \mathrm{~min}, 94^{\circ} \mathrm{C}\right)$, primer annealing $\left(1 \mathrm{~min}, 55^{\circ} \mathrm{C}\right)$, and primer extension $\left(1 \mathrm{~min}, 74^{\circ} \mathrm{C}\right)$. The reaction mixture components were identical to those described above.

All PCRs were performed in a Biomed type 60 thermocycler (Biomed, Theres, Germany), and after amplification, the DNA fragments were length separated by electrophoresis through 0.8 to $2 \%$ agarose gels in $40 \mathrm{mM}$ Tris-acetate ( $\mathrm{pH} 7.4)-1$ $\mathrm{mM}$ EDTA- $0.33 \mu \mathrm{g}$ of ethidium bromide per ml. Results were documented by Polaroid photography by using a Land camera and Polapan 556 high-speed films.

\section{RESULTS}

Patients and environmental screening. (i) Outbreak. Within a period of 45 days during the early summer of 1994, five patients from the hematology ward at the University Hospital Dijkzigt were diagnosed with invasive aspergillosis (Fig. 1). During the preceding 24 months, only two patients in the same ward had been diagnosed with invasive aspergillosis. This indicated a sudden and significant increase in infection incidence. Aspergillus spp. were cultured from BAL fluid from two patients, without the simultaneous culturing of other pathogens. Both patients had chest X-rays consistent with invasive aspergillosis. Aspergillus spp. were also cultured from biopsy material from the eyes, from the mastoid air cells, and from the sinuses sphenoidales of an additional three patients (Table 2). No other microorganisms were cultured from these biopsy materials. Calco Fluor White stainings clearly showed the true invasiveness of the fungi. After prophylactic regimens were started, no additional patients were diagnosed with invasive aspergillosis.

(ii) Air samples. Large numbers of aspergilli were cultured from air samples taken from the outside air and, albeit at lower densities, from air samples taken within the hospital (Table 3). Only on two occasions did the number of aspergilli cultured from samples taken on the hematology ward exceed the numbers cultured from samples taken from other departments. On both occasions the organism in question was $A$. flavus. Two HEPA-filtered rooms also yielded significant growth of $A$. flavus on these occasions. Air samples taken at a nearby demolition site showed heavy growth of aspergilli ( $A$. fumigatus, $A$. flavus, and $A$. niger). However, the number of conidia sharply decreased away from this site.

(iii) Air-conditioning and filtration systems. In the first 2 weeks that the old hematology ward was closed, the number of aspergilli cultured sharply decreased. Air samples taken from above the ceiling plates after this period showed no growth of fungi, and neither did swabs taken from surfaces that looked suspect. All samples taken from within the air-conditioning and filtration systems failed to grow aspergilli. Swabs taken from HEPA filters and pieces of these filters placed on Sabouraud plates also revealed no fungal growth. Fungal isolates (all $A$. fumigatus) were obtained from the inlet filters of the HEPA filtration systems.

Fungal strains and DNA typing. (i) Fungal isolates. Two isolates of $A$. flavus were collected from patients with invasive disease, hospitalized in the hematology ward. An additional strain was obtained from the sputum of a patient on another ward. Twenty-five isolates were obtained from air samples taken during the study period. Nineteen additional strains were obtained from other institutions (Table 4). 


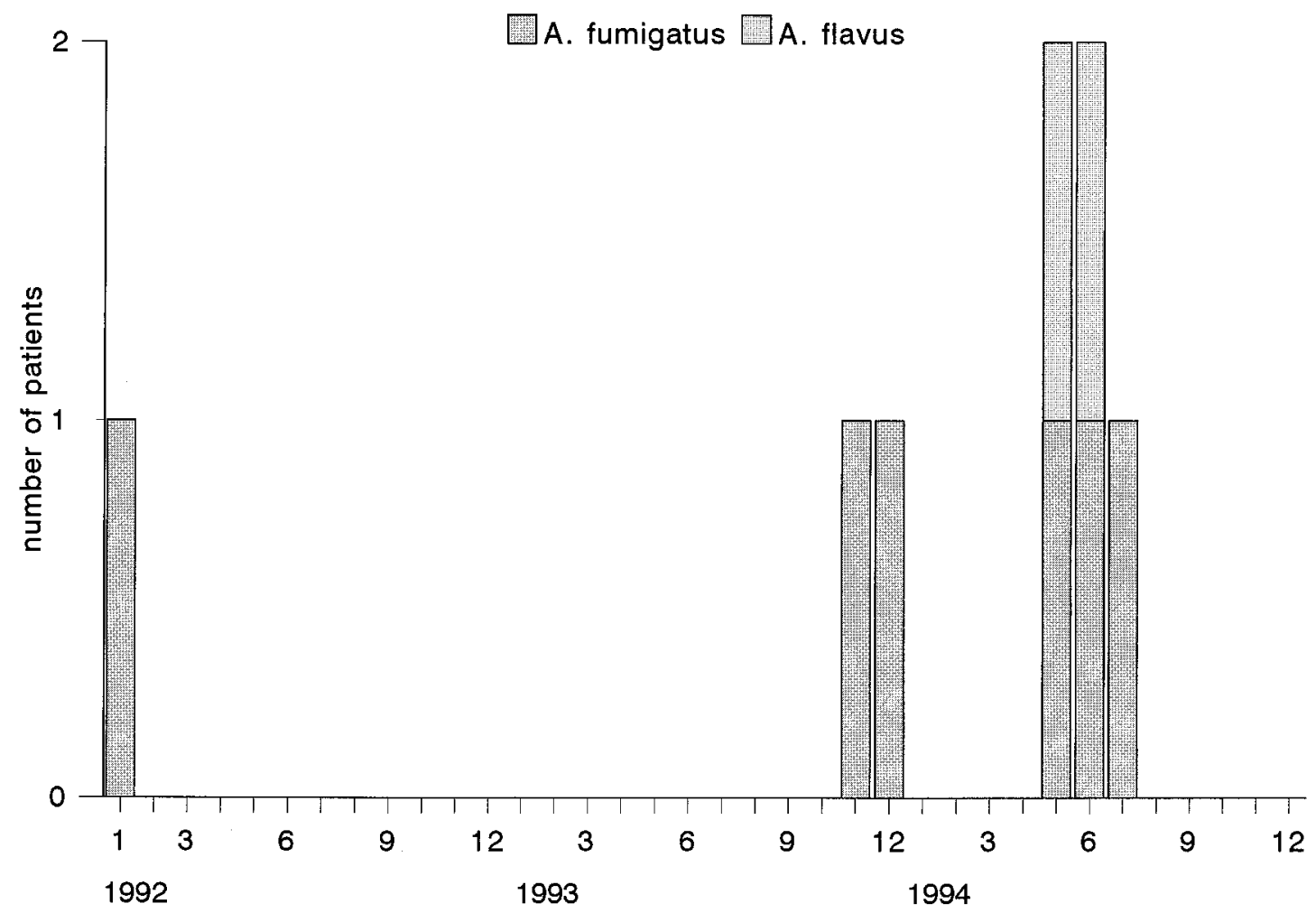

FIG. 1. Number of patients diagnosed with invasive aspergillosis between 1992 and 1994 . The numbers 1 to 12 on the $x$ axis correspond to the months January to December.

Three isolates of $A$. fumigatus from patients with invasive infection in the hematology ward and four clinical isolates from patients on other wards were collected. From the environment, eight strains isolated during the study period were chosen randomly (Table 5).

(ii) Fungal DNA isolation. The protocol combining grinding and immediate lysis in guanidium isothiocyanate-containing buffers enabled high-efficiency, high-quality DNA isolation. DNA preparations thus obtained allowed reproducible results by RAPD analysis. This was tested by using different batches of DNA isolated on different days from different fungal strains (data not shown).

(iii) Comparing isolates of $\boldsymbol{A}$. flavus. Full-scale RAPD analysis was first performed on a selection of the strains from Rotterdam $(n=12)$ (Table 4; Fig. 1$)$. Several different types were discovered: of 12 isolates, 6 appeared to be unique, whereas 1 pattern was found 6 times. Analysis of 16 additional strains from Rotterdam, with three RAPD primers only, revealed genetic heterogeneity in this group; 7 different strains could be distinguished (data not shown). The pattern that was common among the first group was again found to be common, occurring nine times. The other strains appeared to be unique. Overall, 15 of the 28 nosocomial isolates were identical or highly similar; one of these was a strain recovered from one of the patients with invasive disease (patient 4 ). The combined RAPD patterns of each of the two other clinical isolates were unique.

The $A$. flavus isolates from within the Academic Hospital Rotterdam could be distinguished from those obtained from the other institutions. Moreover, these latter isolates could be differentiated from each other, although identical RAPD results were sometimes found within geographically clustered groups (for instance, H3 [884] and H6 [985] [Fig. 2]). Documentation of possible epidemiological relationships between these strains was not available. Among the strains from the University Hospital Nijmegen, five had been derived from a single deceased patient. Interestingly, post-mortem strains cultured from different organs of this patient were identical but they differed from a strain isolated from BAL fluid taken before death.

TABLE 2. Patients with invasive disease caused by $A$. flavus or $A$. fumigatus

\begin{tabular}{|c|c|c|c|c|}
\hline $\begin{array}{c}\text { Patient (gender } \\
\text { and age }[\mathrm{yr}] \text { ) }\end{array}$ & $\begin{array}{l}\text { Hematological } \\
\text { disease }\end{array}$ & $\begin{array}{c}\text { Date (day-mo-yr) of diagnosis of } \\
\text { Aspergillus infection }\end{array}$ & $\begin{array}{l}\text { Clinical manifestation; } \\
\text { pathogen }\end{array}$ & Outcome \\
\hline $1(\mathrm{~F}, 38)$ & Multiple myeloma & $27-05-94$ & Endophthalmitis; $A$. fumigatus & Alive \\
\hline $2(\mathrm{M}, 37)$ & Acute myeloid leukemia & $01-06-94$ & Invasive external otitis; $A$. flavus & Alive \\
\hline $3(\mathrm{M}, 53)$ & Acute lymphocytic leukemia & $30-06-94$ & Pneumonia; A. fumigatus & Alive \\
\hline $4(\mathrm{M}, 65)$ & Aplastic anemia & $02-07-94$ & Sinusitis; A. flavus & Died \\
\hline $5(\mathrm{M}, 40)$ & Chronic myeloid leukemia & $10-07-94$ & Pneumonia; A. fumigatus & Died \\
\hline
\end{tabular}

\footnotetext{
${ }^{a} \mathrm{~F}$, female; M, male.
} 
TABLE 3. Number of CFU of all fungi (pathogenic and nonpathogenic) in the hospital air and the surroundings during various study periods

\begin{tabular}{lccc}
\hline \multirow{2}{*}{ Period $^{a}$} & \multicolumn{3}{c}{ Fungus CFU $^{b}$} \\
\cline { 2 - 4 } & Outside & Hematology ward & HEPA-filtered rooms \\
\hline I & $530(0.9)$ & $9.1(0.04)$ & $2.0(0.02)$ \\
II & $340(1.3)$ & $2.4(0.02)$ & $0.3(0)$ \\
III & $200(1.1)$ & $0.8(0)$ & $0.5(0.03)$ \\
\hline
\end{tabular}

${ }^{a}$ Period I is the outbreak period, period II is the 2 weeks in which the ward was closed, and period III is the period in which the air-conditioning systems were opened and examined. Numbers shown are the average CFU per cubic meter deduced from totals of $15 \mathrm{~m}^{3}$ (outside), $20 \mathrm{~m}^{3}$ (HEPA-filtered rooms), or $50 \mathrm{~m}^{3}$ (hematology ward).

${ }^{b}$ The first number refers to all fungi; the number in parentheses refers to Aspergillus spp. only.

PCR ribotyping identified two types among the $A$. flavus strains. Most of the isolates generated two amplimers ( 750 and $650 \mathrm{bp}$ in length), whereas a subset of strains gave rise to the 750-bp fragment only. This limited degree of polymorphism did not add to that revealed by the RAPD assays. One of the three American A. flavus strains (U3 [isolate no. 31 (506857)] was the single exception in the sense that only a 450-bp fragment was synthesized. We assume that this particular strain does not represent $A$. flavus.

(iv) Comparing isolates of $\boldsymbol{A}$. fumigatus. Results of RAPD analysis for the 15 strains studied are shown in Fig. 1; the interpretation is summarized in Table 5. Nearly all isolates of A. fumigatus could be differentiated by RAPD analysis using different primers. One RAPD type (overall RAPD type II) was found three times; all other combinations were unique. No RAPD identity between environmental and clinical isolates was found. The PCR ribotyping assay resulted in the amplification of a 1,200-bp DNA fragment for all the strains, thereby unambiguously identifying the species as $A$. fumigatus.

(v) General remarks. Figure 2 highlights that in the RAPD patterns, species-specific DNA fragments (present in all lanes) could be observed. In this way, isolates of $A$. flavus and $A$. fumigatus could be discriminated quite easily. This was further confirmed by additional experiments using various other primers (data not shown). From the overall number of types detectable per primer species, it can be concluded that for both $A$. flavus and $A$. fumigatus combined application of primers 5 and 6 results in adequate demonstration of genetic polymor-

TABLE 4. PCR typing of nosocomial and environmental $A$. flavus isolates

\begin{tabular}{|c|c|c|c|c|c|c|c|c|c|c|c|}
\hline \multirow{2}{*}{ Isolate no. } & \multirow{2}{*}{ Code } & \multirow{2}{*}{ Source $^{a}$} & \multirow{2}{*}{$\begin{array}{l}\text { Isolation date } \\
\text { (day-mo-yr) }\end{array}$} & \multicolumn{7}{|c|}{ Genotype with PCR primer species: } & \multirow{2}{*}{$\begin{array}{l}\text { Overall RAPD } \\
\text { type }^{b}\end{array}$} \\
\hline & & & & 26 & 28 & $3-4$ & $5-6$ & E1 & E2 & sp1-sp2 & \\
\hline $1^{c}$ & $2-9$ & Sinusitis & 02-07-94 & A & A & A & A & A & A & A & I \\
\hline $2^{c}$ & $1-76$ & Invasive external otitis & 01-06-94 & B & B & $\mathrm{B}$ & B & B & B & B & II \\
\hline 3 & $6-3$ & Sputum (patient outside hematology ward) & 22-07-94 & $\mathrm{C}$ & A & $\mathrm{C}$ & $\mathrm{C}$ & A & A & A & III \\
\hline 4 & $2-45$ & HEPA (hematology ward) & 07-07-94 & A & A & A & A & A & A & A & I \\
\hline 5 & $4-62$ & Hematology ward & 19-07-94 & A & A & A & A & A & A & A & I \\
\hline 6 & $2-15$ & Hematology ward & 04-07-94 & $\mathrm{D}$ & $\mathrm{C}$ & $\mathrm{D}$ & $\mathrm{D}$ & $\mathrm{C}$ & B & B & IV \\
\hline 7 & $2-36$ & Internal ward & $06-07-94$ & A & A & A & A & A & A & A & I \\
\hline 8 & $6-46$ & Environment & $05-08-94$ & $\mathrm{E}$ & $\mathrm{D}$ & $\mathrm{E}$ & $\mathrm{E}$ & A & A & A & $\mathrm{V}$ \\
\hline 9 & $4-61$ & Hematology ward & $19-07-94$ & A & A & A & A & A & A & A & I \\
\hline 10 & $4-70$ & Hematology ward & $19-07-94$ & A & A & A & A & A & A & A & I \\
\hline 11 & $5-73$ & Environment & $26-07-94$ & $\mathrm{~F}$ & $\mathrm{C}$ & $\mathrm{F}$ & $\mathrm{F}$ & $\mathrm{D}$ & $\mathrm{C}$ & A & VI \\
\hline 12 & $5-33$ & Environment & $18-07-94$ & G & $\mathrm{E}$ & G & $\mathrm{G}$ & A & $\mathrm{C}$ & B & VII \\
\hline 13 & 143 & Superficial isolate, RLH & $\mathrm{NA}^{d}$ & $\mathrm{H}$ & $\mathrm{F}$ & $\mathrm{ND}^{e}$ & $\mathrm{H}$ & $\mathrm{E}$ & $\mathrm{D}$ & A & VIII \\
\hline 14 & 2062 & Superficial isolate, RLH & NA & I & $\mathrm{C}$ & A & I & $\mathrm{F}$ & A & A & IX \\
\hline 15 & 884 & Superficial isolate, RLH & NA & $\mathrm{J}$ & G & A & $\mathrm{J}$ & A & $\mathrm{E}$ & A & $\mathrm{X}$ \\
\hline 16 & 1826 & Superficial isolate, RLH & NA & I & $\mathrm{H}$ & $\mathrm{H}$ & $\mathrm{K}$ & $\mathrm{F}$ & $\mathrm{F}$ & $\mathrm{B}$ & XI \\
\hline 17 & 1220 & Superficial isolate, $\mathrm{RLH}$ & NA & $\mathrm{K}$ & I & I & $\mathrm{L}$ & G & $\mathrm{G}$ & $\mathrm{B}$ & XII \\
\hline 18 & 985 & Superficial isolate, RLH & NA & $\mathrm{J}$ & G & A & $\mathrm{J}$ & A & $\mathrm{E}$ & A & $\mathrm{X}$ \\
\hline 19 & 137 & Superficial isolate, AHN & NA & $\mathrm{C}$ & $\mathrm{J}$ & $\mathrm{C}$ & $\mathrm{C}$ & A & A & A & XIII \\
\hline 20 & 284 & Bronchial isolate, $\mathrm{AHN}$ & NA & $\mathrm{L}$ & $\mathrm{J}$ & $\mathrm{K}$ & $\mathrm{N}$ & $\mathrm{F}$ & I & B & XIV \\
\hline 21 & 509 & BAL isolate, $\mathrm{AHN}$ & NA & $\mathrm{M}$ & $\mathrm{J}$ & $\mathrm{K}$ & $\mathrm{N}$ & $\mathrm{F}$ & I & B & $\mathrm{XV}$ \\
\hline 22 & 510 & Obduction isolate, $\mathrm{AHN}$ & NA & $\mathrm{N}$ & $\mathrm{K}$ & $\mathrm{L}$ & $\mathrm{O}$ & $\mathrm{H}$ & $\mathrm{J}$ & B & XVI \\
\hline 23 & 511 & Obduction isolate, $\mathrm{AHN}$ & NA & $\mathrm{N}$ & $\mathrm{K}$ & $\mathrm{L}$ & $\mathrm{O}$ & $\mathrm{H}$ & $\mathrm{J}$ & B & XVI \\
\hline 24 & 512 & Obduction isolate, AHN & NA & $\mathrm{N}$ & $\mathrm{K}$ & $\mathrm{L}$ & $\mathrm{O}$ & $\mathrm{H}$ & $\mathrm{J}$ & $\mathrm{B}$ & XVI \\
\hline 25 & 513 & Obduction isolate, $\mathrm{AHN}$ & NA & $\mathrm{N}$ & $\mathrm{K}$ & $\mathrm{L}$ & $\mathrm{O}$ & $\mathrm{H}$ & $\mathrm{J}$ & B & XVI \\
\hline 26 & 544 & Abdominal isolate, AHN & NA & $\mathrm{O}$ & $\mathrm{J}$ & $\mathrm{M}$ & $\mathrm{P}$ & I & $\mathrm{K}$ & $\mathrm{A}$ & XVII \\
\hline 27 & 744 & Superficial isolate, AHN & NA & $\mathrm{C}$ & $\mathrm{L}$ & $\mathrm{C}$ & $\mathrm{C}$ & $\mathrm{J}$ & $\mathrm{L}$ & A & XVIII \\
\hline 28 & 1023 & Superficial isolate, AHN & NA & $\mathrm{J}$ & $\mathrm{J}$ & $\mathrm{N}$ & $\mathrm{J}$ & $\mathrm{K}$ & $\mathrm{M}$ & A & XIX \\
\hline 29 & 432619 & Clinical isolate, USA & NA & $\mathrm{P}$ & $\mathrm{M}$ & $\mathrm{O}$ & $\mathrm{Q}$ & A & $\mathrm{C}$ & A & $\mathrm{XX}$ \\
\hline 30 & 433771 & Clinical isolate, USA & NA & Q & $\mathrm{N}$ & $\mathrm{P}$ & $\mathrm{R}$ & $\mathrm{L}$ & $\mathrm{N}$ & A & XXI \\
\hline 31 & 506857 & Clinical isolate, USA & NA & $\mathrm{R}$ & $\mathrm{O}$ & Q & $\mathrm{S}$ & M & $\mathrm{O}$ & $\mathrm{C}$ & XXII \\
\hline Total no. of types & & & & 18 & 15 & 17 & 19 & 13 & 15 & 3 & 22 \\
\hline
\end{tabular}

${ }^{a}$ RLH, Regional Laboratory of Public Health Haarlem; AHN, Academic Hospital Nijmegen; USA, Diagnostic Microbiology Laboratory of the University of Minnesota (Minneapolis).

${ }^{b}$ The overall PCR type was based on the number of differing banding patterns when results for all assays were combined.

${ }^{c}$ Clinical isolate of patient listed in Table 2 .

${ }^{d} \mathrm{NA}$, not available.

${ }^{e} \mathrm{ND}$, not done. 
TABLE 5. PCR typing of nosocomial and environmental A. fumigatus isolates

\begin{tabular}{|c|c|c|c|c|c|c|c|c|c|c|c|}
\hline \multirow{2}{*}{ Isolate no. } & \multirow{2}{*}{ Code } & \multirow{2}{*}{ Source $^{a}$} & \multirow{2}{*}{$\begin{array}{l}\text { Isolation date } \\
\text { (day-mo-yr) }\end{array}$} & \multicolumn{7}{|c|}{ Genotype with PCR primer species: } & \multirow{2}{*}{$\begin{array}{l}\text { Overal } \\
\text { RAPD } \\
\text { type }^{b}\end{array}$} \\
\hline & & & & 26 & 28 & $3-4$ & $5-6$ & E1 & E2 & sp1-sp2 & \\
\hline 1 & $2-2$ & CF patient outside hematology ward & 01-06-94 & A & A & A & A & A & A & A & I \\
\hline 2 & $3-2$ & Hematology ward & 09-07-94 & A & A & B & B & $\mathrm{B}$ & B & A & II \\
\hline 3 & $3-3$ & Hematology ward & 09-07-94 & A & A & B & B & $\mathrm{B}$ & B & A & II \\
\hline 4 & $3-25$ & Environment & $13-07-94$ & $\mathrm{~B}$ & $\mathrm{~B}$ & $\mathrm{C}$ & $\mathrm{C}$ & $\mathrm{C}$ & $\mathrm{C}$ & A & III \\
\hline 5 & $4-9$ & Environment & $11-07-94$ & A & $\mathrm{C}$ & $\mathrm{D}$ & $\mathrm{D}$ & $\mathrm{D}$ & $\mathrm{D}$ & A & IV \\
\hline 6 & $2-1$ & $\begin{array}{l}\text { BAL sample from patient outside } \\
\text { hematology ward }\end{array}$ & 04-07-94 & $\mathrm{C}$ & $\mathrm{C}$ & $\mathrm{D}$ & $\mathrm{E}$ & $\mathrm{E}$ & $\mathrm{E}$ & A & $\mathrm{V}$ \\
\hline 7 & $3-58$ & Hematology ward & $12-07-94$ & $\mathrm{C}$ & A & A & $\mathrm{F}$ & $\mathrm{B}$ & B & A & VI \\
\hline 8 & $2-57$ & Environment & 08-07-94 & A & $\mathrm{C}$ & A & G & $\mathrm{F}$ & A & A & VII \\
\hline 9 & $2-32$ & Internal ward & $06-07-94$ & A & A & $\mathrm{E}$ & $\mathrm{H}$ & G & $\mathrm{F}$ & A & VIII \\
\hline 10 & $5-1$ & Environment & $12-07-94$ & $\mathrm{D}$ & B & A & $\mathrm{E}$ & $\mathrm{H}$ & G & A & IX \\
\hline $11^{c}$ & $2-4$ & BAL sample from hematologic patient & $30-06-94$ & $\mathrm{C}$ & $\mathrm{C}$ & $\mathrm{E}$ & $\mathrm{E}$ & I & $\mathrm{H}$ & A & $\mathrm{X}$ \\
\hline 12 & $2-3$ & Pancreatitis & $10-06-94$ & $\mathrm{C}$ & $\mathrm{B}$ & $\mathrm{B}$ & I & $\mathrm{J}$ & I & A & $\mathrm{XI}$ \\
\hline $13^{c}$ & $5-26$ & BAL sample from hematologic patient & $10-07-94$ & $\mathrm{E}$ & $\mathrm{D}$ & $\mathrm{F}$ & $\mathrm{J}$ & $\mathrm{K}$ & $\mathrm{J}$ & A & XII \\
\hline $14^{c}$ & $6-71$ & Eye of hematologic patient & $27-05-94$ & A & $\mathrm{C}$ & $\mathrm{ND}^{d}$ & ND & $\mathrm{L}$ & ND & A & XIII \\
\hline 15 & $2-6$ & Abdominal drain & $30-05-94$ & A & A & $\mathrm{B}$ & $\mathrm{B}$ & $\mathrm{B}$ & $\mathrm{B}$ & A & II \\
\hline Total no. of types & & & & 5 & 4 & 6 & 10 & 12 & 10 & 1 & 13 \\
\hline
\end{tabular}

${ }^{a} \mathrm{CF}$, cystic fibrosis.

${ }^{b}$ The overall PCR type was based on the number of differing banding patterns when results for all assays were combined.

${ }^{c}$ Clinical isolate of patient listed in Table 2.

${ }^{d} \mathrm{ND}$, not done.

phisms, even though the use of additional primers resulted in further differentiation.

\section{DISCUSSION}

Nosocomial aspergillosis still poses a significant clinical problem $(1,13,18)$. Although PCR tests for detection of fungi have been described recently $(16,20)$, this does not yet alleviate the clinical burden. At present, PCR techniques appear to be more useful for the typing of fungal isolates $(3,11)$. Conclusions concerning relatedness of clinical and environmental isolates have often been based on biochemical and species similarities only. Using these parameters, one would have concluded that the apparent outbreak of invasive aspergillosis encountered in the summer of 1994 in the University Hospital Rotterdam was due to at least two different species and that clinical and environmental strains of each species might be identical. More information and stronger evidence for the relatedness of clinical and environmental strains can be derived from analyzing their genomes. For this purpose, specialized PCR techniques are currently being introduced in clinical mycology laboratories $(3,7,8,11,14,21,24)$. In the present study, RAPD assays were applied for the analysis of an outbreak of invasive aspergillosis due to both $A$. flavus and $A$. fumigatus.

Before using RAPD analysis in epidemiologic surveys, one has to evaluate the extent of the differences in DNA banding patterns that can be generated. The present study showed that RAPD analysis could discriminate between strains of $A$. flavus and $A$. fumigatus. Strains of $A$. flavus could also be discriminated in this way, but additional discrimination was needed. In preliminary assays with 24 primers and various combinations thereof, five additional primers, which increased the degree of genetic heterogeneity, were selected. Differences among PCR fingerprints obtained for different strains of $A$. flavus appeared smaller than those obtained for strains of $A$. fumigatus. This may indicate more-limited chromosomal variation in the former species or a different genome composition, requiring other primers. This phenomenon was previously described for
A. nidulans, for which species the spread of a single clone in extensive areas was reported in surveillance studies (6).

Combination of different RAPD assays discriminated among nearly all strains of Aspergillus spp. In contrast, PCR ribotyping presented $A$. fumigatus strains as a homogeneous group: only a single amplimer was generated. With $A$. flavus, two ribotypes were detected. It has recently been proposed that PCR ribotyping may present a broad-spectrum strategy suited for typing of all sorts of bacterial species (10). However, the resolution of this procedure is unacceptably low for Aspergillus sp. typing studies.

By RAPD analysis, all patients' strains of $A$. flavus appeared to be genetically different. RAPD analysis of the whole collection of environmental and nosocomial strains of $A$. flavus repeatedly identified one specific genotype among the nosocomial strains. These identical patterns were not caused by a lack of discriminative power of the RAPD technique, for several strains of $A$. flavus collected in other laboratories could be discriminated with relative ease.

Thus, among the $A$. flavus strains encountered in the University Hospital Rotterdam, a single clone appeared to predominate on the hematology ward involved in the outbreak. We consider two options as possible epidemiological explanations. First, it is possible that this particular strain was brought to the hospital by the index patient, from whom it subsequently spread into the hospital environment: the highest concentrations of spores of the common A. flavus type were found during the days that the patient was diagnosed with this infection. This possible kind of spread of conidia from a patient or from patient materials has not been described previously. Alternatively, it is possible that this patient may have been infected by conidia deriving from an environmental source within or in the immediate vicinity of the hospital. However, no such source could be detected upon detailed screening of the wards involved; no fungi were detected in the air-conditioning systems or on the HEPA filters. No rotting wood or aspergilli growing on isolation materials were detected. No fungi were grown from the samples taken from above the ceiling plates. This 


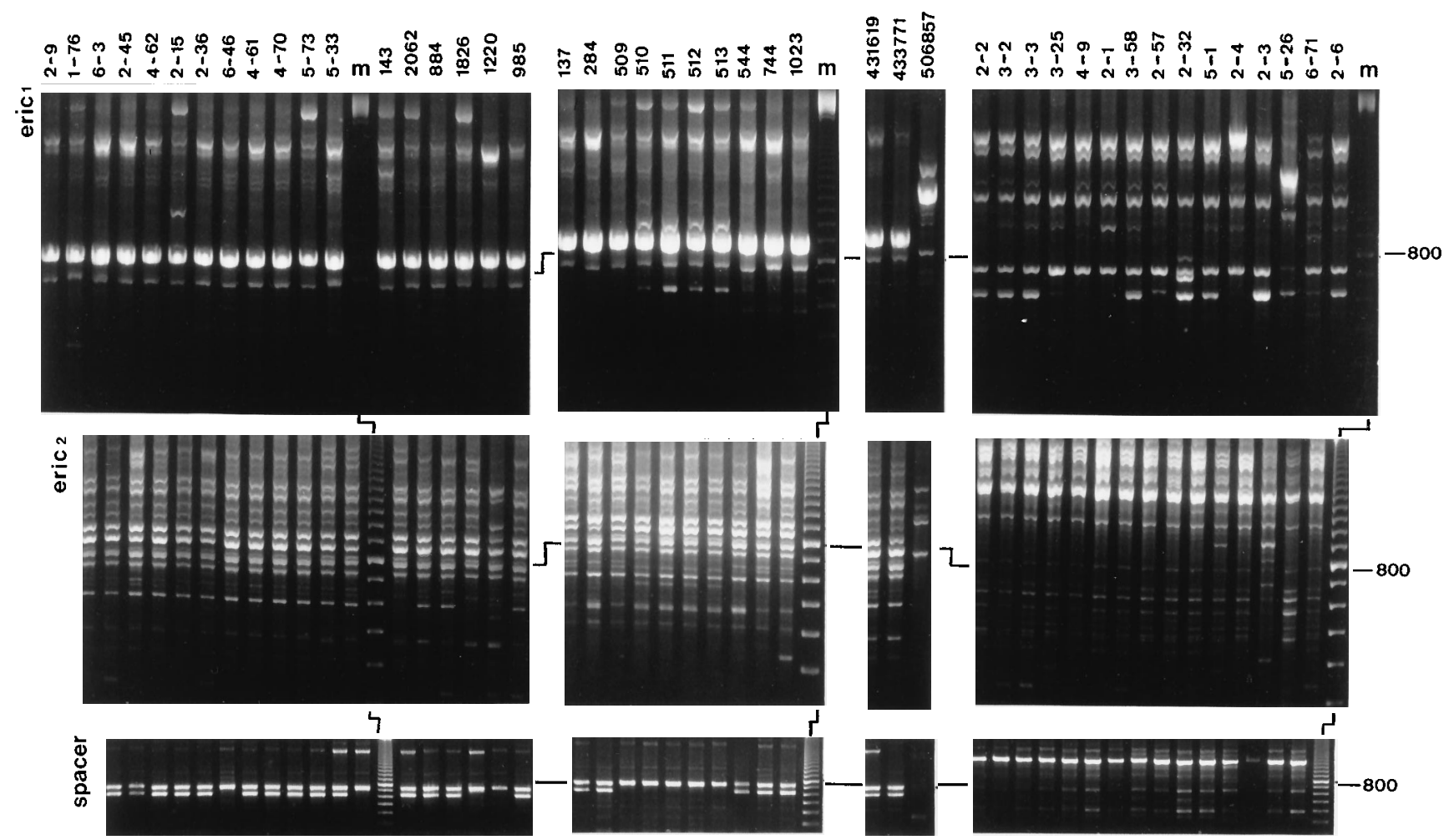

FIG. 2. PCR typing of nosocomial and environmental isolates of $A$. flavus and A. fumigatus strains. The $A$. flavus strains are shown in the left-hand part of the figure (beginning with lanes 2-9 and ending with lane 506857). The numbers given above the lanes correspond with the codes given in Table 4. In the right-hand part of the figure, results obtained with the A. fumigatus strains are displayed. The numbering above the lines (2-2 through 2-6) corresponds with the codes given in Table 5. Lanes marked " $\mathrm{m}$ " contain the molecular length marker, of which the prominent 800-bp fragment is indicated on the right. The top panel shows results of arbitrarily primed PCR performed with primer ERIC-1, the middle panel shows the ERIC-2 data, and the bottom panel illustrates the ribotyping as performed for all fungal strains. For these tests, the sp1-sp2 primer pair was employed. The interpretation of the results is given in Tables 4 and 5 .

strain may have been present prior to the infection period, but no strains isolated during this period are available. In addition, no construction activities took place within the hospital at the time of this apparent outbreak. The heavy growth of aspergilli from the air samples taken at a nearby demolition site may have had marginal influence. However, at a distance of $75 \mathrm{~m}$ from this site no increase in the numbers of Aspergillus sp. spores in comparison with numbers in control samples was found (the hospital is situated $150 \mathrm{~m}$ from this site).

As we did not find genetic relatedness among the clinical isolates, it is unlikely that the outbreak was a result of conidia spreading from one single source within the hospital. This outbreak may have been the result of generally elevated numbers of conidia from several Aspergillus sp. clones present in the outside air. Seasonal variation in Aspergillus sp. spore density has been reported (17). Why large numbers of conidia entered the hospital remains unanswered. With renewed instructions for handling the air-conditioning systems of HEPAfiltered rooms, a policy to keep windows closed at all times, and continued air sampling, it is hoped that subsequent outbreaks can be prevented.

If knowledge concerning the genetic relatedness of clinical and environmental isolates is available early in the course of an apparent outbreak of invasive aspergillosis, it is possible to start searching for a specific cause. Nonrelatedness of isolates should lead to investigations of the functioning of the barrier systems, while relatedness of isolates should induce a search for a common source.

Therefore, we recommend genotyping and comparison of nosocomial and environmental isolates of Aspergillus spp. obtained during outbreaks of invasive aspergillosis as soon as possible. RAPD analysis is a truly rapid and reliable tool at such times.

\section{ACKNOWLEDGMENTS}

We gratefully acknowledge the generous supply of $A$. flavus strains by Jacques Meis, Paul Verwey, and Ton Reis (Department of Medical Microbiology, University Hospital Nijmegen); F. Rhame and P. Ferrieri (Diagnostic Microbiology Laboratory, University of Minnesota); and Ed Ijzerman (Regional Laboratory for Public Health, Haarlem). We thank Marian Humphrey for critically reviewing the manuscript.

\section{REFERENCES}

1. Andriole, V. T. 1993. Infections with Aspergillus species. Clin. Infect. Dis. 17(Suppl. 2):S481-S486.

2. Arnow, P. M., M. Sadigh, C. Costas, D. Weil, and R. Chudy. 1991. Endemic and epidemic aspergillosis associated with in-hospital replication of Aspergillus organisms. J. Infect. Dis. 164:998-1002.

3. Aufauvre-Brown, A., J. Cohen, and D. W. Holden. 1992. Use of randomly amplified polymorphic DNA markers to distinguish isolates of Aspergillus fumigatus. J. Clin. Microbiol. 30:2991-2993.

4. Boom, R., C. J. A. Sol, M. M. M. Salimans, C. L. Jansen, P. M. E. Wertheim van Dillen, and J. Van der Noordaa. 1990. Rapid and simple method for purification of nucleic acids. J. Clin. Microbiol. 28:495-503.

5. Cartwright, C. P., F. Stock, S. E. Beekmann, E. C. Williams, and V. J. Gill. 1995. PCR amplification of rRNA intergenic spacer regions as a method for epidemiologic typing of Clostridium difficile. J. Clin. Microbiol. 33:184-187.

6. Geiser, D. M., M. L. Arnold, and W. E. Timberlake. 1994. Sexual origins of British Aspergillus nidulans isolates. Proc. Natl. Acad. Sci. USA 91:2349-2352.

7. Girardin, H., J.-P. Latgé, T. Srikantha, B. Morrow, and D. R. Soll. 1993. Development of DNA probes for fingerprinting Aspergillus fumigatus. J. Clin. Microbiol. 31:1547-1554. 
8. Girardin, H., J. Sarfati, F. Traore, J. Dupouy Camet, F. Derouin, and J. P. Latge. 1994. Molecular epidemiology of nosocomial invasive aspergillosis. J. Clin. Microbiol. 32:684-690.

9. Gurtler, V. 1993. Typing of Clostridium difficile strains by PCR amplification of variable length 16S-23S rDNA spacer regions. J. Gen. Microbiol. 139: 3089-3097.

10. Kostman, J. R., M. B. Alden, M. Mair, T. D. Edlind, J. J. LiPuma, and T. L. Stull. 1995. A universal approach to bacterial molecular epidemiology by polymerase chain reaction ribotyping. J. Infect. Dis. 171:204-208.

11. Loudon, K. W., J. P. Burnie, A. P. Coke, and R. C. Matthews. 1993. Application of PCR to fingerprinting Aspergillus fumigatus by random amplification of polymorphic DNA. J. Clin. Microbiol. 31:1117-1121.

12. Maslow, J. N., M. E. Mulligan, and R. D. Arbeit. 1993. Molecular epidemiology: application of contemporary techniques to the typing of microorganisms. Clin. Infect. Dis. 17:153-164.

13. McWhinney, P. H. M., C. C. Kibbler, M. D. Hamon, O. P. Smith, L. Gandhi, L. A. Berger, R. K. Walesby, A. V. Hoffbrand, and H. G. Prentice. 1993. Progress in the diagnosis and management of aspergillosis in bone marrow transplantation: 13 years' experience. Clin. Infect. Dis. 17:397-404.

14. Niesters, H. G. M., W. H. F. Goessens, J. F. G. M. Meis, and W. G. V. Quint. 1993. Rapid polymerase chain reaction-based identification assays for Candida species. J. Clin. Microbiol. 31:904-910.

15. Pfaller, M. A. 1992. Epidemiological typing methods for mycoses. Clin. Infect. Dis. 14(Suppl. 1):S4-S10.

16. Reddy, L. V., A. Kumar, and P. Kurup. 1993. Specific amplification of Aspergillus fumigatus DNA by PCR. Mol. Cell. Probes 7:121-126.

17. Rhame, F. S. 1991. Prevention of nosocomial aspergillosis. J. Hosp. Infect. 18:466-472.
18. Ruutu, P., V. Valtonen, L. Tiitanen, E. Elonene, L. Volin, P. Veijalainen, and T. Ruutu. 1987. An outbreak of invasive aspergillosis in a hematology unit. Scand. J. Infect. Dis. 19:347-351.

19. Seeliger, H. P. R., and K. Tintelnot. 1988. Epidemiology of aspergillosis, p. 23-35. In E. Vanden Bossche, D. W. R. MacKenzie, and G. Cauwenbergh (ed.), Aspergillus and aspergillosis. Plenum Press, New York.

20. Spreadbury, C., D. Holden, A. Aufauvre Brown, B. Bainbridge, and J. Cohen. 1993. Detection of Aspergillus fumigatus by polymerase chain reaction. J. Clin. Microbiol. 31:615-621.

21. Tang, C. M., J. Cohen, A. J. Rees, and D. W. Holden. 1994. Molecular epidemiological study of invasive pulmonary aspergillosis in a renal transplantation unit. Eur. J. Clin. Microbiol. Infect. Dis. 13:318-321.

22. Tompkins, L. S., F. C. Tenover, and A. Arvin. 1994. New technology in the clinical microbiology laboratory: what you always wanted to know but were afraid to ask. J. Infect. Dis. 170:1068-1074.

23. Van Belkum, A. 1994. DNA fingerprinting of medically important microorganisms by use of PCR. Clin. Microbiol. Rev. 7:174-184.

24. Van Belkum, A., W. Melchers, B. E. De Pauw, S. Scherer, W. Quint, and J. F. G. M. Meis. 1994. Genotypic characterisation of sequential Candida albicans isolates from fluconazole treated neutropenic patients. J. Infect. Dis. 169:1062-1070.

25. Van Belkum, A., W. Mol, R. van Saene, L. M. Ball, D. Van Velzen, and W. G. V. Quint. 1994. PCR mediated genotyping of Candida albicans strains from bone marrow transplant patients. Bone Marrow Transplant. 13:811815.

26. Versalovic, J., T. Koeuth, and J. R. Lupski. 1991. Distribution of repetitive DNA sequences in eubacteria and application to fingerprinting of bacterial genomes. Nucleic Acids Res. 19:6823-6831. 